Seminar Nasional Teknologi Informasi dan Kedirgantaraan (SENATIK)

Vol. II, 26 November 2016, ISSN: 2528-1666

\title{
SISTEM PENDUKUNG KEPUTUSAN PENGADAAN BAHAN PUSTAKA PERPUSTAKAAN STT ADISUTJIPTO MENGGUNAKAN METODE TOPSIS
}

\author{
Anton Setiawan Honggowibowo \\ Program Studi Teknik Informatika \\ Sekolah Tinggi Teknologi Adisutjipto \\ Jl Janti Blok R Lanud Adisutipto, Yogyakarta \\ antons h@yahoo.com
}

\begin{abstract}
Library STT Adisutjipto still use manual for procurement of library materials. So that the workers have to put together a list of books needs of various departments request then selects request books one by one so often is not appropriate in the procurement process. To overcome these problems will be built a decision support system that can provide an alternative solution in the procurement process book. By using TOPSIS librarian can take a few titles that have the greatest value of any calculation, so that will be obtained several lists of books that will be held. TOPSIS method aims to select an alternate book based on criteria (budget, proposals, books are often borrowed, price, edition of the book, stock, date of publication and publisher) which has been determined. The calculation process is done by finding the weight value of each alternative on each criterion. The selected book is the greatest value as the best alternative. The final result of the calculation method TOPSIS with manual calculation is the same, where the book Ansi (BKO6) is a book that has the greatest value. The value for each method is BK06 with a value of 0.7781 on TOPSIS and BK06 to the value of 0.7781 on manual calculations.
\end{abstract}

Keywords: TOPSIS, Library, Procurement, Decision

\section{Pendahuluan}

Perpustakaan merupakan tempat penyimpanan dan pemeliharaan bahan pustaka untuk menunjang pelaksanaan akademis perguruan tinggi. Perpustakaan dapatmembantumahasiswa dan dosen serta pengunjung lainnya untuk meningkatkan dan memajukan ilmu pengetahuan. Selain itu perpustakaan harus mampu mengelola, melestarikan dan mengembangkan koleksi bahan pustaka / buku untuk memenuhi kebutuhan informasi yang dibutuhkan jurusan ataupun program studi dan seluruh pengguna perpustakaan. Solusi pemanfaatan teknologi informasi dalam mendukung kegiatan perpustakaan akan memudahkan petugas dalam mendapatkan data dan informasi secara cepat, tepat dan akurat sehingga efektivitas dan efisiensi kerja tercapai.
Mekanisme pengadaan bahan pustaka perpustakaan di STT Adisutjipto Yogyakarta masih menggunakan cara manual, petugas belum dapat mengetahui buku apa yang paling banyak dipinjam. Petugas perpustakaan mengumpulkan daftar kebutuhan buku yang dibutuhkan mahasiswa dari berbagai permintaan jurusan kemudian menyeleksi permintaan tersebut satu persatu sehingga sering kali di dalam prosesnya tidak bisa memenuhi kebutuhan buku baru yang sesuai dengan minat mahasiswa.

Dari uraian di atas penulis ingin menganalisa pengadaan bahan pustaka yang dibutuhkan mahasiswa dengan menggunakan metode TOPSIS. Metode TOPSIS adalah metode untuk penyelesaian keputusan dengan banyak kriteria, sehingga dapat menghasilkan nilai akhir. Metode TOPSIS secara tepat akan menghasilkan nilai yang baik dalam pengambilan keputusan. Analisa ini bermanfaat bagi 
petugas perpustakaan untuk memperoleh informasi pembelian bahan pustaka baru yang sesuai dengan kebutuhan. Oleh karena itu diperlukan sebuah aplikasi yang dapat menentukan bahan pustaka apa yang akan dibeli agar bisa bermanfaat bagi mahasiswa berdasarkan tiap angkatan dalam periode tertentu.

\section{Metode Penelitian}

Dalam penulisan ini akan dilakukan penelitian dengan melalui tahapan-tahapan sebagai berikut :

1. Metode Pengumpulan Data

a. Metode Pengamatan (Observasi)

Metode pengumpulan data yang dilakukan dengan cara mengamati secara langsung ke perpustakaan STT Adisutjipto Yogyakarta.

b. Metode Wawancara (Interview)

Data-data yang diperoleh dengan melakukan wawancara atau tanya jawab secara langsung kepada narasumber yaitu petugas perpustakaan STT Adisutjipto Yogyakarta.

c. Metode Kepustakaan

Metode pengumpulan data kepustakaan ini untuk mendapatkan konsep teori mengenai masalah yang berhubungan dengan pengamatan, pembuatan program, serta mencari sumber data yang dibukukan atau jurnal yang telah ada sebelumnya.

2. Analisa Kebutuhan Sistem

Data yang dibutuhkan dalam pembuatan pengadaan bahan pusaka perpustakaan adalah data buku yang dipinjam, data buku, dan data usulan buku yang dibutuhkan oleh mahasiswa.

3. Perancangan sistem

Dalam pengadaan buku perpustakaan(Studi Kasus

: STT Adisutjipto Yogyakarta) menggunakan perhitungan metode TOPSIS. Setelah metode memperoleh hasil nilai akhir, petugas membuat ranking setiap nilai dan kemudian ranking dibandingkan untuk memperoleh calon judul buku yang sama untuk pengadaan.

4. Implementasi Sistem

Software dalam aplikasi pengadaan bahan pustaka perpustakaan adalah bahasa pemrograman Delphi 7 dan Oracle XE 11g.

5. Pengujian Sistem

Pengadaan buku perpustakaan akan melakukan uji sistem dengan membandingkan hasil akhir dari metode TOPSIS. Hasil pengujian akhir sistem didapatkan dari nilai perhitungan program dan nilai perhitungan manual.

\subsection{Analisa Kebutuhan Data}

Dalam pengadaan buku di perpustakaan STT Adisutjipto Yogyakarta, ada beberapa tahap yang akan dilakukan untuk analisa data pada proses penentuan buku yang akan diadakan yaitu :

a. Data Buku yang Dipinjam

Data buku dipinjam adalah data buku yang sering dipinjam oleh anggota perpustakaan. Data ini akan diproses oleh sistem ketika anggota perpustakaan melakukan transaksi peminjaman buku.

b. Data Buku

Data keseluruhan jumlah buku yang dimiliki perpustakaan. Admin menambahkan jumlah buku pada sistem sesuai pengadaan ataupun pembelian buku baru setiap periodenya.

c. Data Usulan

Data ini diperoleh dari saran maupun usulan anggota perpustakaan yang membutuhkan buku baru. Data usulan diproses oleh admin dengan mempertimbangkan jumlah buku yang tersedia di perpustakaan. Apabila jumlah buku tidak sesuai dengan kebutuhan mahasiswa, maka pengadaan buku baru akan dilakukan.

Analisis proses sistem menggunakan metode TOPSIS. Metode TOPSIS diterapkan dalam kasus pengadaan buku yang akan dibeli, buku baru dipilih dengan mempertimbangkan beberapa kriteria, yaitu anggaran, buku yang sering dipinjam, harga buku, edisi buku, stok buku, tahun terbit, dan penerbit.

Untuk melakukan perhitungan metode TOPSIS, langkah ke- 1 adalah dengan memberi nilai dan membuat tabel keputusan. Kemudian yang ke- 2 dengan memberi bobot setiap kriteria yang telah ditentukan. Judul buku dan semua kriteria dibuat tabel keputusan ternormalisasi adalah tahap ke- 3 . Proses ke- 4 dengan menggunakan rumus menormalisasikan data pada tabel normalisasi. Langkah ke- 5 adalah membuat normalisasi berbobot dengan bobot kriteria. Mencari nilai maksimal dan nilai minimal dari tabel normalisasi berbobot adalah perhitungan ke- 6 . Proses ke- 7 adalah mencari nilai Decision Matrix Positive (D+) dan Decision Matrix Negative (D-) disetiap alternatif, dan perhitungan terakhir yaitu mencari Nilai Preferensi Alternatif(V). 
Alternatif dapat diranking berdasarkan urutan nilai V. Maka dari itu alternatif terbaik adalah salah satu yang memiliki jarak terpendek terhadap solusi ideal dan berjarak terjauh dengan solusi negatif ideal.

Kemudian diperoleh ranking dari tiap calon buku sebagai pendukung keputusan pengadaan buku di perpustakaan, maka semakin tinggi nilai ranking, kesempatan buku untuk diadakan semakin besar, begitu pula sebaliknya.

\subsection{Relasi Antar Tabel}

Perancangan relasi antar tabel bertujuan agar relasi antar tabel terhubung dari satu dengan lainnya. Perancangan relasi antar tabel dapat dilihat pada Gambar 1 berikut.

Keterangan Gambar 1 :
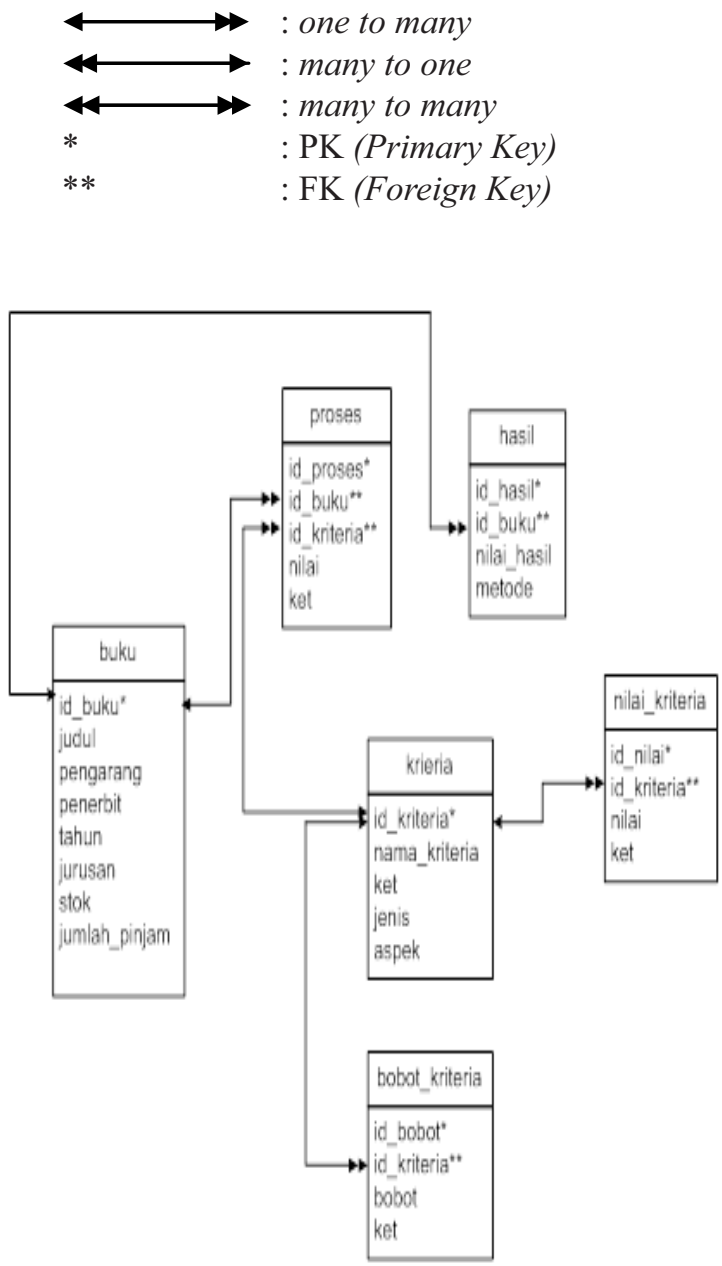

Gambar 1 Relasi Antar Tabel

\subsection{Diagram Alur Data (DAD)}

\subsubsection{Diagram Konteks}

Diagram konteks adalah diagram level tertinggi dari Diagram Alur Data (DAD) yang menggambarkan hubungan sistem dengan lingkungan luarnya. Adapun diagram konteks dari sistem pendukung keputusan pengadaan buku adalah pada Gambar 2.

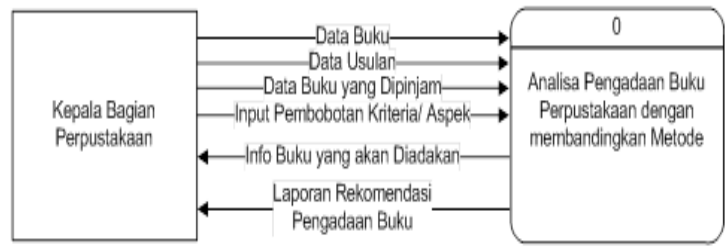

Gambar 2 Diagram Konteks

\subsubsection{Diagram Alur Data Level 1 Pengadaan Buku}

Diagram ini akan memberikan gambaran secara keseluruhan mengenai sistem, baik berupa proses-proses yang berlangsung, aliran data, entitas dan penyimpanan data.

Pada DAD level 1 Data User merupakan awal sistem berjalan sebagai user, maka user akan diminta untuk login. Untuk dapat melakukan login dan masuk ke menu utama, user mengisi data username dan password yang telah dimiliki. Adapun DAD level 1 dari sistem pendukung keputusan pengadaan buku adalah pada Gambar 3 .

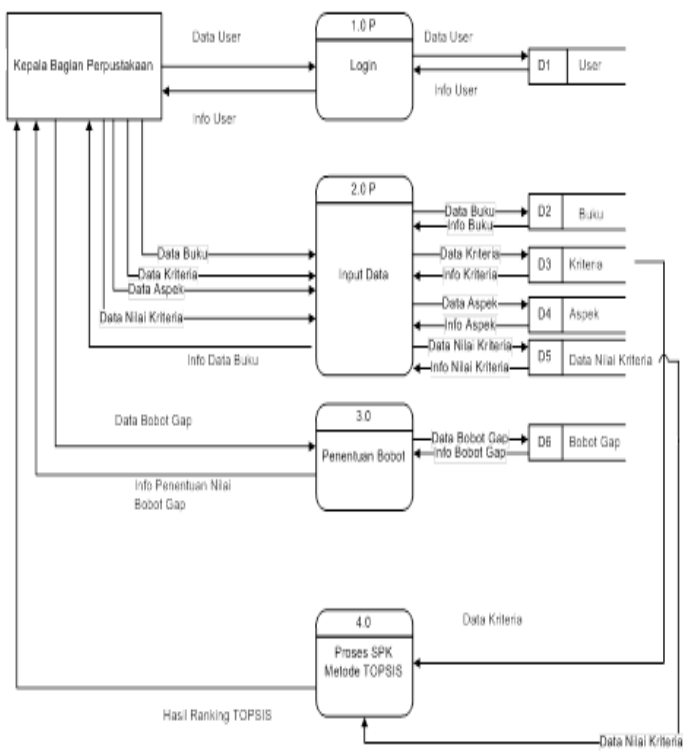

Gambar 3 Diagram Alur Data (DAD) Level 1 


\subsubsection{Diagram Alur Data Level 2 Proses 4 Master Data Pengadaan Buku}

Pada DAD level 2 proses 4 Master Data merupakan penjabaran bagian master data. Dalam proses ini, user sebagai pengguna dalam pengujian sistem akan dapat menginputkan, mengedit, dan menghapus data buku. Dalam proses ini user juga melakukan perhitungan dengan menggunakan metode TOPSIS. Setelah itu, akan dikembalikan kepada user sebagai output (keluaran) dalam bentuk grafik yang diberikan oleh sistem. DAD level 2 proses 4 Master Data dapat digambarkan pada Gambar 4.

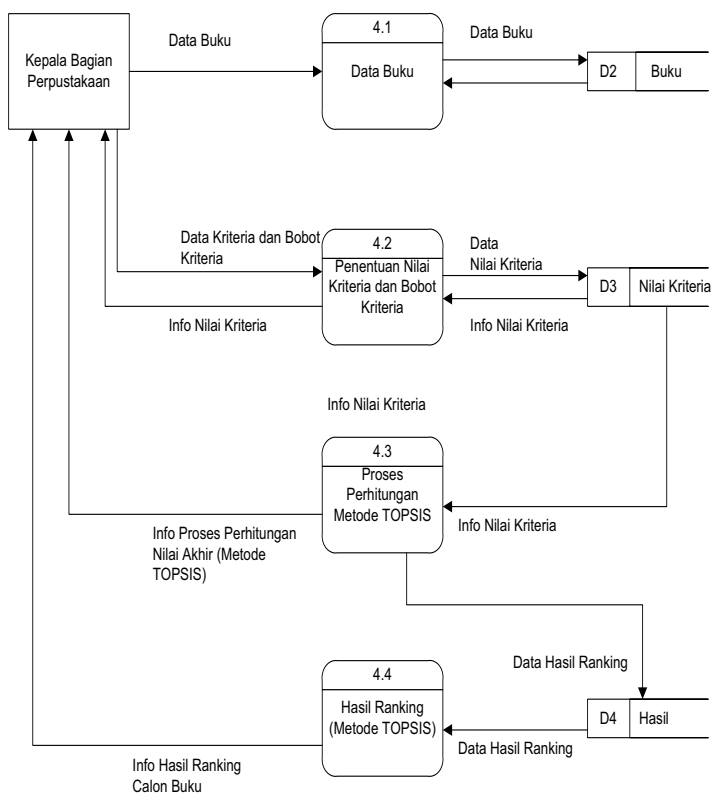

Gambar 4 Diagram Alur Data (DAD) Level 2 Proses 4

\section{Hasil dan Pembahasan}

\subsection{Implementasi Sistem}

Implementasi sistem merupakan suatu tahapan, di mana sistem tersebut diletakkan setelah melalui perancangan sistem. Tujuan dari implementasi sistem ini adalah sistem yang telah dibuat sesuai dengan rancangan sistem yang telah dirancang sebelumnya. Sistem ini dioperasikan sesuai dengan yang diharapkan.

\subsubsection{Tampilan Kriteria}

Submenu kriteria merupakan simpanan data untuk penentuan kriteria pengadaan buku. Pada tampilan ini terdapat tombol tambah untuk memperbaharui data, tombol hapus untuk menghapus data, dan tombol keluar untuk kembali pada menu utama. Tampilan submenu kriteria terdapat pada Gambar 5.

DATA KRITERIA
\begin{tabular}{|l|l|l|l|}
\hline id_kriteria & nama_kriteria & jenis & ket \\
\hline C1 & anggaran & CF & dana yang disediakan dari kampus \\
\hline C2 & usulan buku & CF & usulan buku dari mahasiswa dan dosen \\
\hline C3 & buku yang sering dipinjam & SF & buku yang keterpakaiannya paling tinggi \\
\hline C4 & harga buku & SF & harga buku dipasaran \\
\hline C5 & edisi buku & SF & buku edisi ke berapa \\
\hline C6 & stok buku & SF & jumlah buku yang tersedia \\
\hline C7 & tahun terbit & SF & tahun buku diterbitkan \\
\hline C8 & penerbit & SF & nama penerbit buku \\
\hline
\end{tabular}

Gambar 5 Kriteria

\subsubsection{Tampilan Proses Metode}

Proses metode merupakan perhitungan data buku dengan menggunakan metode TOPSIS pada sistem. Calon buku setiap jurusan dihitung dengan metode, kemudian akan menghasilkan hasil nilai akhir. Terdapat tombol cek data untuk melihat data sebelum diproses, tombol metode TOPSIS untuk perhitungan TOPSIS. Tampilan submenu proses metode terdapat pada Gambar 6.

Tabel Data Normalisasi
\begin{tabular}{|l|l|l|l|l|l|l|l|l|}
\hline & C1 & C2 & C3 & C4 & C5 & C6 & C7 & C8 \\
\hline BK01 & 4 & 4 & 3 & 4 & 5 & 3 & 4 & 4 \\
\hline BK02 & 4 & 3 & 3 & 4 & 5 & 4 & 5 & 5 \\
\hline BK03 & 5 & 4 & 5 & 5 & 4 & 3 & 5 & 5 \\
\hline BK04 & 3 & 4 & 3 & 3 & 4 & 4 & 4 & 4 \\
\hline BK05 & 4 & 4 & 5 & 4 & 4 & 3 & 4 & 4 \\
\hline BK06 & 5 & 5 & 5 & 5 & 4 & 4 & 5 & 4 \\
\hline BK07 & 3 & 4 & 4 & 4 & 4 & 4 & 5 & 4 \\
\hline BK08 & 5 & 4 & 5 & 5 & 5 & 2 & 5 & 5 \\
\hline BK09 & 5 & 5 & 5 & 5 & 4 & 3 & 5 & 5 \\
\hline BK10 & 4 & 4 & 4 & 4 & 4 & 3 & 4 & 4 \\
\hline & & & & & & & \\
\hline & & & & & & & \\
\hline & & & & & & & & \\
\hline 4.8 & & & & & & & \\
\hline
\end{tabular}

Gambar 6 Proses Metode

\subsubsection{Tampilan Hasil Perhitungan}

Hasil perhitungan merupakan hasil akhir perhitungan dengan metode TOPSIS. Hal ini digunakan untuk melihat hasil perhitungan ranking setiap jurusan dengan menggunakan metode TOPSIS. Tampilan hasil ranking terdapat pada Gambar 7.

\subsubsection{Tampilan Laporan}

Laporan merupakan tampilan hasil ranking yang dapat di-print out. Klik radio button preview 


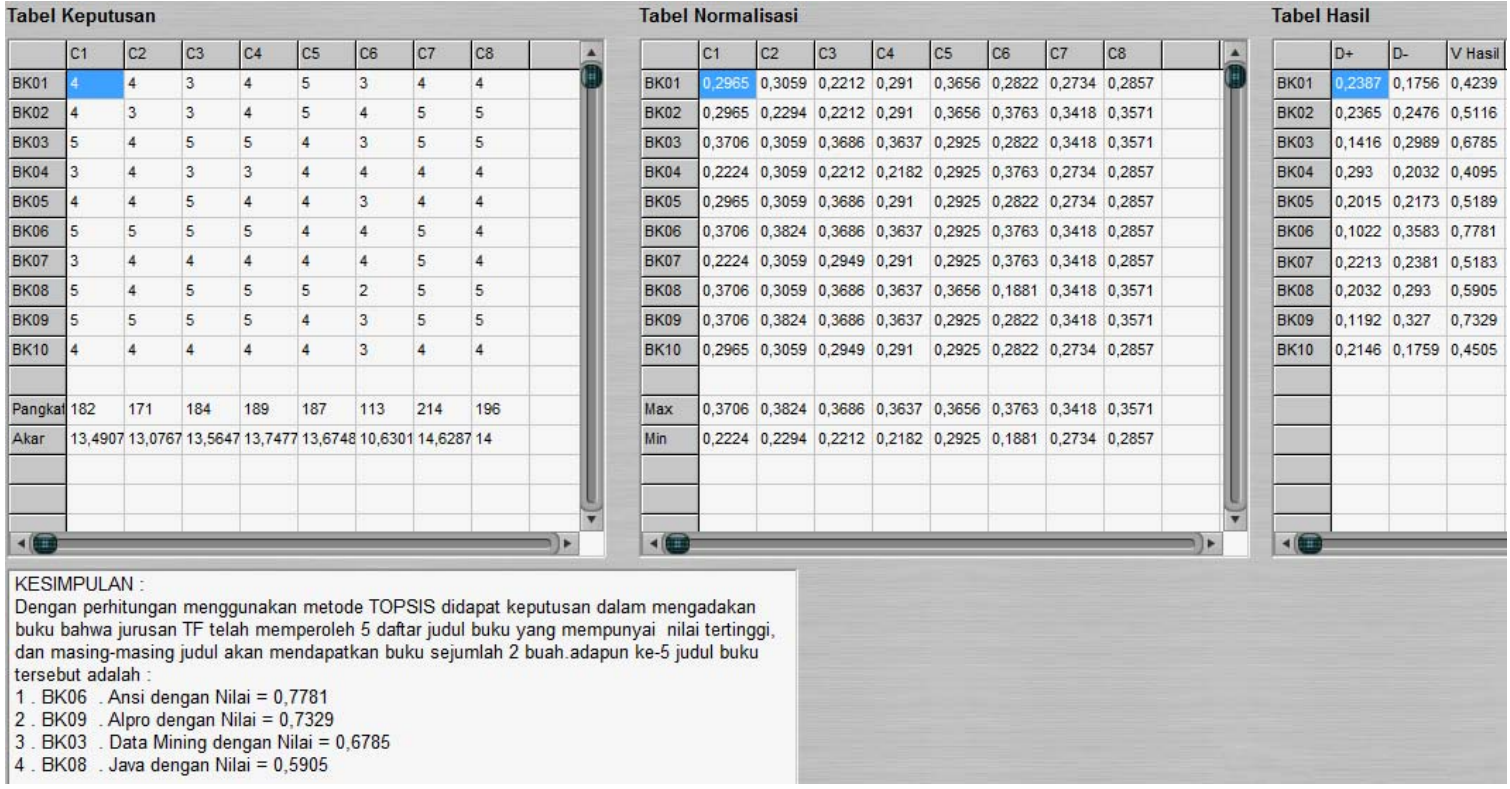

Gambar 7 Hasil TOPSIS

untuk melihat hasil preview laporan sebelum diprint. Tampilan laporan dapat dilihat pada Gambar 8 dan Gambar 9 berikut :

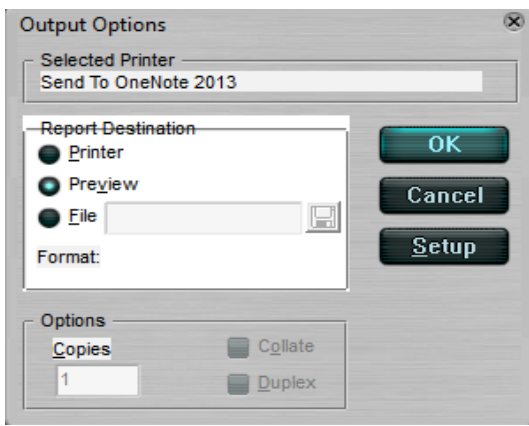

Gambar 8 Output

Metode TOPSIS

\begin{tabular}{|c|c|c|c|}
\hline No & ID Buku & Judul & Nilai \\
\hline TF & BK06 & Ansi & 0,7781 \\
\hline TF & BK09 & Alpro & 0,7329 \\
\hline TF & BK03 & Data Mining & 0,6785 \\
\hline TF & BK08 & Java & 0,5905 \\
\hline
\end{tabular}

\subsection{Analisa Hasil Metode TOPSIS}

Pada hasil metode TOPSIS yang mendapatkan nilai tertinggi adalah buku Ansi dengan id buku BK06 $=0,7781$. Kemudian peringkat ke- 2 adalah buku Alpro dengan id buku BK09 dengan nilai $=0,7329$ dan seterusnya. Pada TOPSIS proses penyelesaiannya dilakukan dengan menghitung kriteria dengan bobot kriteria yang sudah ditentukan nilai kriterianya. Dengan membuat tabel normalisasi berbobot pada TOPSIS, kemudian mencari nilai D menggunakan nilai maksimal dan nilai minimal. Setelah itu mencari nilai $\mathrm{V}$ hasil dengan menghitung nilai D+ dan D-. Berikut adalah Tabel 1 merupakan hasil perhitungan manual Metode TOPSIS.

Tabel 1 Hasil Perhitungan Manual Metode TOPSIS

\begin{tabular}{|c|c|c|}
\hline \multicolumn{3}{|c|}{ Metode TOPSIS } \\
\hline Id Buku & Judul Buku & Nilai \\
\hline BK06 & Ansi & 0.7781 \\
\hline BK09 & Alpro & 0.7329 \\
\hline BK03 & Data Mining & 0.6785 \\
\hline BK08 & Java & 0.5905 \\
\hline
\end{tabular}

Gambar 9 Preview 


\begin{tabular}{|c|c|c|c|}
\hline & $\mathrm{D}+$ & D- & $V$ Hasil \\
\hline BK01 & 0,2387 & 0,1756 & 0,4239 \\
\hline $\mathrm{BK} 02$ & 0,2365 & 0,2476 & 0,5116 \\
\hline $\mathrm{BK} 03$ & 0,1416 & 0,2989 & 0,6785 \\
\hline $\mathrm{BKO} 4$ & 0,293 & 0,2032 & 0,4095 \\
\hline BK05 & 0,2015 & 0,2173 & 0,5189 \\
\hline BK06 & 0,1022 & 0,3583 & 0,7781 \\
\hline BK07 & 0,2213 & 0,2381 & 0,5183 \\
\hline BK08 & 0,2032 & 0,293 & 0,5905 \\
\hline BK09 & 0,1192 & 0,327 & 0,7329 \\
\hline BK10 & 0,2146 & 0,1759 & 0,4505 \\
\hline
\end{tabular}

Gambar 10 Hasil Perhitungan Aplikasi dengan Metode TOPSIS

Dari Tabel 1 dan Gambar 10 dapat dilihat perbandingan nilai dari setiap judul buku, hasil diurutkan dari nilai yang paling besar ke-nilai yang paling kecil.

Berikut adalah keterangan dari hasil perhitungan yang memiliki nilai terbesar yang diperoleh dengan menggunakan metode TOPSIS : Buku Ansi yang memiliki id buku BK06 dengan nilai masing-masing kriteria sebagai berikut kriteria anggaran bernilai 5 poin (harga lebih sama dengan Rp 200.000,-), kriteria usulan buku bernilai 5 poin (jumlah usulan yang diberikan adalah lebih sama dengan 12 usulan), kriteria buku yang sering dipinjam bernilai 5 poin (dalam periode tertentu buku dipinjam oleh anggota perpustakaan sebanyak lebih sama dengan 20 kali), kriteria harga buku bernilai 5 poin (harga buku Ansi adalah lebih sama dengan Rp $100.000,-)$, kriteria edisi buku bernilai 4 poin (edisi buku ansi adalah edisi ke-4), kriteria stok buku bernilai 4 poin (jumlah stok buku Ansi di perpustakaan adalah sebanyak 6-7 buku), kriteria tahun terbit bernilai 5 poin (tahun terbit buku Ansi adalah 2014), dan kriteria terakhir adalah penerbit bernilai 4 poin (buku Ansi diterbitkan oleh Informatika - Bandung).

\section{Kesimpulan}

Dari hasil penelitian, perancangan dan implementasi yang telah dilakukan dapat ditarik kesimpulan sebagai berikut :
1. Analisa Pengadaan Buku Perpustakaan dengan menggunakan Metode TOPSIS ini menggunakan 8 kriteria.

2. Aplikasi pengujian yang dibuat mampu memberikan hasil dengan metode TOPSIS.

3. Analisa Pengadaan Buku Perpustakaan dengan menggunakan Metode TOPSIS ini digunakan untuk memilih judul buku yang akan diadakan di perpustakaan STTAdisutjipto Yogyakarta sesuai dengan kriteria yang telah ditentukan.

\section{Saran}

Saran yang dapat diberikan guna untuk perbaikan dan pengembangan dari aplikasi ini adalah :

1. Diharapkan melalui hasil penelitian ini mampu menjadi tolak ukur pemilihan metode bagi peneliti yang ingin membangun sistem pendukung keputusan.

2. Untuk peneliti selanjutnya aplikasi ini dapat dikembangkan menjadi sistem yang dinamis agar bisa dilakukan lagi pengkajian ulang terhadap kriteria penilaian buku dan kemungkinan adanya penambahan kriteria untuk pengadaan buku perpustakaan.

\section{Ucapan Terima Kasih}

Penulis mengucapkan terima kasih kepada Sekolah Tinggi Teknologi Adisutjipto Yogyakarta yang telah memberi dukungan financial terhadap penelitian ini.

\section{DAFTAR PUSTAKA}

[1] Basuki, Sulistyo., 1991, Pengantar Ilmu Perpustakaan, Gramedia Pustaka Utama, Jakarta.

[2] Desi, 2013, Sistem Pendukung Keputusan Pemilihan Laptop dengan Metode TOPSIS, Pelita Informatika Budi Darma, Volume : III, Nomor : 2, April 2013, ISSN : 2301-942.

[3] Gorry, G.A., and M.S. Scott Morton., 1971, A Framework for Management Information Systems, Sloan Management Review, USA.

[4] Hartono, 2005, Analisis dan Desain Sistem Pendukung Keputusan, Andi Offset, Yogyakarta. 
[5] Hwang, C.L., dan Yoon, K., 1981, Multiple Attribute Decision Making : Methods and Applications, Springer-Verlag, New York.

[6] Kusrini, 2007, Konsep dan Aplikasi Sistem Pendukung Keputusan, Andi Offset, Yogyakarta.

[7] Susilo, Djoko., 2004, Perancangan dan Implementasi Komponen Visual pada Delphi, Graha Ilmu, Yogyakarta.
[8] Turban, Aronson, Liang., 2005, Decision Support System and Intelligent System Seventh Edition, Pearson/ Prentice Hall, New Jersey.

[9] Wiratmoko, 2013, Sistem Pendukung Keputusan Rekomendasi Pengadaan Buku Perpustakaan PENS Dengan Metode AHP, Prosiding Seminar Nasional TEKNOIN, Volume : 3, ISBN 978-602-14272-0-0. 